\title{
El mito de Sīyāvuš y las leyendas actuales de Bujará ${ }^{1}$
}

\section{The myth of Sīyāvuš and the present legends of Bukhara}

\author{
SHEKOUFEH MOHAMMADI SHIRMAHALEH \\ Universidad Nacional Autónoma de México, México
}

Resumen: El mito de Sīyāvuš es uno de los más antiguos e importantes del mundo iranio y existen numerosos rituales relacionados con él. Sīyāvuš es una deidad de las plantas cuya muerte y resurrección anual garantiza el reverdecer de la naturaleza tras las estaciones frías. Hoy en día, este mito sigue vigente en Irán y Asia Central gracias a las leyendas que se han derivado de él. En el presente trabajo se exponen algunas de estas leyendas, recogidas en trabajo de campo en 2018, y se reinterpretan en el marco del nombrado mito.

Palabras clave: Sīyāvuš; Shahnamé de Ferdousí; mitos iranios; leyendas de Asia Central.

Abstract: The myth of Sīyāvuš is one of the oldest and most important in the Iranian world and many rituals are related to it. Sīyāvuš

Recepción: 6 de diciembre de 2018. / Aceptación: 23 de marzo de 2019.

${ }^{1}$ Este trabajo se realizó gracias al apoyo del Programa de Apoyo a Proyectos de Investigación e Innovación Tecnológica (PAPIT): IA 400518, El recorrido literario del mito de Siyawash desde el Shahnamé de Ferdousí hasta el Sendebar medieval. 
is a deity of plants whose death and annual resurrection guarantees nature's rebirth after cold seasons. To this day, it remains a powerful influence in Iran and Central Asia thanks to the legends that have sprung up from it. This paper describes some of these legends, collected during a fieldwork trip in 2018, and reinterprets them in reference to this myth.

Keywords: Sìyāvuš; Ferdowsi’s Shahnameh; Iranian myths; Central Asia legends.

Nuestro objetivo es exponer nuevos puntos de vista acerca del mito de Sīyāvuš y su vigencia en la ciudad de Bujará, Uzbekistán. El mito de Sīyāvuš es uno de los más importantes del mundo iranio antiguo, que abarcaba vastos territorios de Asia Central, y de los más actuales. Hay numerosos estudios sobre las diferentes dimensiones de este mito y las leyendas épicas que se han derivado de él, especialmente en Irán. Sin embargo, a excepción de trabajos realizados a finales del siglo XIX $\mathrm{y}$ principios del $\mathrm{xx}$, mayormente por parte de orientalistas soviéticos, escasean investigaciones que abarquen Asia Central y especialmente Uzbekistán.

Mis argumentos parten del Libro de reyes o Shahnamé, del poeta persa Abul Qasem Ferdousí y que contiene el registro escrito más completo del mito, y se fundamentan en el viaje de investigación y trabajo de campo que realicé en Uzbekistán en marzo de 2018. La razón de elegir como centro el Shabnamé es tanto su relevancia como única fuente escrita del mito como su antigüedad, pues aunque se compuso en el siglo XI, se trata de una obra que recoge leyendas orales del vasto territorio iranio antiguo que datan, al menos, del siglo vil a.e.c. Las demás obras escritas que se tomaron en cuenta también son textos antiguos, y en ellas se puede rastrear con más claridad la huella de las versiones orales del mito, ${ }^{2}$ pues la finalidad de este viaje era registrar otras interpretaciones de la leyenda

${ }^{2}$ Las fuentes secundarias y más recientes acerca de este tema (en ruso, uzbeko u otras lenguas) serán consideradas en otros trabajos. 
de Sīyāvuš que difirieran de las recogidas en el actual Irán (Anyaví Shirazí, 1984). Para cumplir este objetivo tracé, basándome en el Shahnamé, una ruta de viaje que incluyera todas las ciudades por las que Sīyāvuš había pasado al entrar en el mítico Tūrán, y que se encuentran en el actual Uzbekistán: Termez, Chach (Tashkent), Samarcanda y Bujará. Aunque Bujará fue la última ciudad en la que Sīyāvuš vivió - también fue ahí donde murió-, seguí mi trayecto hasta la ciudad de Jiva, ubicada en la antigua Corasmia, ya que ahí se encuentra Koi Krylgan Kala, el centro ceremonial más importante relacionado con el ritual de luto por Sìyāvuš. En un principio entrevisté a gente local, preguntando si conocían a este personaje y lo que sabían de él; sin embargo, a lo largo del trabajo de campo replanteé las preguntas para centrarlas no en el mito en sí, sino en las experiencias derivadas de él, pues me di cuenta de que, junto a las versiones de la leyenda de Sìyāvuš que circulaban, también se hallaban ecos de ella en las costumbres de los habitantes de Bujará relacionadas con ceremonias funerarias y celebraciones de Nowrūz, el año nuevo persa. Las 47 personas entrevistadas tenían entre 25 y 45 años. A pesar de que el número pudiera parecer pequeño, dada la repetición de los resultados creo que las respuestas se confirman entre sí y, por lo tanto, son representativas.

En este artículo expondré sólo parte de los hallazgos de mi investigación, aquellos relacionados con las leyendas locales que se narran a propósito de algunos monumentos históricos de Bujará. Me familiaricé con dichas leyendas en un principio por el afán de mis intérpretes y guías de mostrarme el orgullo que sentían por su historia, pero después noté que justamente en ellas estaban muchas de las respuestas a mis indagaciones acerca de la supervivencia y la vigencia del mito de Sīyāvuš.

Así pues, comienzo por contextualizar y explicar el mito de Sīyāvuš y algunas prácticas rituales vinculadas a él; posteriormente analizo las leyendas recogidas en este viaje en relación con el mito para destacar las huellas que ha dejado en ellas a 
pesar de haber transcurrido milenios desde su creación y de que Uzbekistán, en su historia, haya pasado por experiencias políticas, sociales, religiosas y culturales muy distintas entre sí que van desde su islamización hasta su dominio por los soviéticos y la secularización posterior.

\section{Sīyāvuš en el espejo del mito y práctica ritual}

El mito de Sīyāvuš es uno de los más conocidos en Asia Central, especialmente en lo que hoy es Uzbekistán y Tayikistán. El culto a esta deidad vegetal ha sido referido desde el siglo IX por historiadores como Biruní (1984) y Narshají (1984), quienes destacan que se trata de rituales con más de 4500 años de antigüedad, y Sìyāvuš ha sido nombrado personaje míticohistórico por Tabarí (1990) y Tha'alibí (1970), entre otros. Los descubrimientos arqueológicos y los estudios antropológicos y etnográficos, en su mayoría realizados por orientalistas europeos desde el siglo XIx, dan fe de lo mismo. El arqueólogo y etnógrafo S. P. Tolstov, por ejemplo, habla de una dinastía de descendientes de Sìyāvuš establecidos en Corasmia desde el siglo vi a.e.c. y la vincula con mitos relacionados con Sīyāvuš en distintas zonas de Corasmia, Sogdia y Persia que datan del segundo milenio a.e.c. (Tolstov, 1984a y 1984b).

Las excavaciones en el sitio de Panjakent en Tayikistán, a su vez, dejaron al descubierto representaciones visuales del ritual de sūg-i Sìyāvuš [luto por Sìyāvuš] practicado en vísperas del año nuevo sogdiano, corasmio y persa, que si bien en los comienzos de los cálculos calendáricos coincidía en las tres zonas y se celebraba en el equinoccio de primavera, con el paso del tiempo y debido a la flexibilidad de los cálculos y a que no se consideraron los años bisiestos, se movió de fecha en Sogdia y Corasmia y se celebraba a veces en los primeros días del invierno, del otoño o del verano (Razí, 1992, p. 228). De todas formas, e independientemente de este mal cálculo, el mencionado ritual tenía que ver con la muerte y la resurrección de 
la naturaleza, y por lo tanto se efectuaba en los últimos cinco días del año viejo dedicados a los difuntos. Las celebraciones de estos días se conocen con el nombre de farvardigán en la tradición mazdea que dominó Persia y Asia Central por varios siglos.

El tema principal de sūg-i Sìyāuuš es el llanto por la muerte de Sīyāvušs, o su viaje al inframundo, que al finalizar el año viejo culmina con la fiesta de su resurrección o regreso al mundo de los vivos, y coincide con la llegada de la primavera y las festividades de Nowrūz (año nuevo). En este sentido, y como deidad vegetal, Sīyāvuš tiene parecido con el Dumuzi y el Tamuz mesopotámicos, con el Osiris egipcio, con Sita en India y Deméter en Grecia. En estos mitos, una deidad, a veces femenina y otras, masculina, es injustamente condenada al inframundo o raptada y enviada ahí, para luego obtener permiso de volver al mundo una vez al año y permanecer durante un periodo aproximado de cuatro a seis meses, lapso que, dependiendo de la zona geográfica, puede abarcar la primavera o el verano.

Los rituales luctuosos realizados para la deidad que garantizaban su regreso del inframundo solían ser muy comunes en Mesopotamia, Persia y Asia Central (Bahar, 2014, pp. 393427), pero la amplitud de la práctica ritual en torno de Sìyāvuš y su vigencia a lo largo de los siglos y hasta la actualidad lo destaca significativamente entre sus pares, pues supera incluso las populares ceremonias mesopotámicas en honor de Dumuzi (Hosurí, 2006, p. 27). En estos ritos, verter lágrimas por la deidad "muerta" es primordial para provocar la empatía y las lágrimas de otros dioses del cielo, lo que se traduce en lluvias para el siguiente año agrícola (Bahar, 2014, p. 429). En Persia, Corasmia y Sogdia, el rito de sūg se acompaña, además, de cantos específicos, música fúnebre y una procesión en la cual los participantes portan una estructura, usualmente de madera de cedro, a veces en forma de trono o ataúd en la que se puede ver la figura de Sìyāvuš. También hay registros de que, en ocasiones, los fieles, vestidos de negro o azul Nilo, 
se flagelan para recordar la sangre derramada de Sìyāvuš (Razí, 1992, p. 271). Esto nos recuerda una diferencia importante entre Sīyāvuš y las demás deidades vegetales mencionadas de la zona: la muerte de Sīyāvuš no es simbólica, como la de Dumuzi o Tamuz - por ejemplo-, que se narra por medio de su condena al inframundo; se trata de una decapitación y es una muerte muy sangrienta e injusta, parecida en algunos aspectos al destino que sufre Osiris.

Ahora bien, ningún documento como el Shahnamé de Ferdousí describe con tantos detalles la vida y la muerte de Sìyāvušs (Ferdousí, 2015, pp. 303-403), y es ahí donde la inocencia y las virtudes de esta deidad, ya convertida en príncipe en el Shabnamé, refuerzan las condiciones injustas de su muerte, que desvelan, más que un asesinato, un sacrificio. Ferdousí cuenta que el hermano del rey Afrāsyāb de Tūrán -territorio mítico de Asia Central- degüella a Sīyāvuš en un desierto utilizando una daga y recoge en una palangana -ambos objetos rituales (Ne'mat Tavusí, 2013, p. 60)- la sangre de la víctima para que no se derrame sobre el suelo, pues tiene miedo de que, al caer en la tierra, su fuerza vital garantice la prevalencia de Sìyāvuš o facilite su resurrección. Sin embargo, según el Shahna$m e ́$, una gota se le escapa al asesino. En el lugar donde cae, nace una planta en cuyas hojas está trazado el rostro de Sīyāvušs. Esta planta y el hijo que había engendrado Sìyāvuš antes de morir, Kay Xusrow, ${ }^{4}$ simbolizan la resurrección del personaje

${ }^{3}$ En el Shahnamé, Sīyāvuš es hijo del rey persa Kāvús. La esposa de éste, Sūdābé, se enamora del joven príncipe, sin igual en belleza, pureza y habilidades, e intenta seducirlo. Cuando no lo consigue, lo acusa de haber intentado abusar de ella. Sìyāvuš se ve obligado a superar una prueba de fuego para mostrar su inocencia. Poco después, se exilia a la tierra enemiga, Tūrán, donde se casa con la hija del rey Afrāsyāb. El hermano del rey lo convence de las malas intenciones de su yerno extranjero y, finalmente, Afrāsyāb ordena el asesinato del inocente príncipe. Las interpretaciones míticas de la vida de Sīyāvuš en Irán son muy importantes para comprender su función como deidad vegetal; sin embargo, están fuera de los límites del presente trabajo, que se centra más en su exilio y su muerte. Basta destacar la función de Sūdābé como la Gran Diosa, pues es la causa del destierro del joven dios vegetal al inframundo/tierra enemiga.

${ }^{4}$ Kay Xusrow es un personaje sumamente importante en los textos sagrados 
mítico en el mundo de las leyendas épicas: Xusrow vengará la sangre de su padre y, al coronarse rey, hará que el mundo, que en ausencia de Sīyāvuš se había secado, reverdezca y se reavive. Aquí hay que añadir que Faranguīs (o Farīgīs), esposa de Sìyāvuš que en ese momento está embarazada de Xusrow, presencia el asesinato. Faranguīs, hija del rey de Turán, ruega a su padre por la vida de su marido, pero Afrāsyāb no sólo no la escucha, sino que intenta matarla a ella también. Las escenas inmediatas anteriores y posteriores al crimen están marcadas por las lágrimas y los sollozos de Faranguīs, acompañados de acciones como soltarse la cabellera, desgarrarse la ropa y arañarse las mejillas (Ferdousí, 2015, p. 393). Esta manera de expresar luto, que no es exclusiva de esta historia, ${ }^{5}$ también se observa en el rito de sūg-i Sìyāuuš, y si bien los participantes pueden ser tanto hombres como mujeres, éstas desempeñan un papel protagónico en la ceremonia que recuerda el duelo de Faranguīs. ${ }^{6}$

\section{La vigencia de la leyenda de Sīyāvuš}

Libros como Tarij-e Bujará [La historia de Bujará] y Asar-ulbagiyah 'an quroon-ul-khaliya [Sobre los signos que permanecen de los siglos pasados], escritos en el siglo x, hablan de la vigen-

del mazdeísmo, así como en las leyendas orales y escritas de Irán y Asia Central. Se le reconoce como hombre inmortal que aparecerá en el fin de los tiempos y apoyará a Sušyānet, la figura mesiánica del mazdeísmo, en su batalla final en contra de Ahrimán. Véase Avestá, Zāmyād Yašt: 92-93; Revayat-e Pablaví, pp. 141-159, citado por Bahar, 2014, p. 280. Por lo tanto, el papel de Xusrow en el Shabnamé, como hijo y símbolo de la resurrección de Sīyāvuš, es paralelo a su función de restablecedor del orden mundial en la visión mazdeísta. Sobre este paralelismo hay muchos estudios cuya mención no cabe en este trabajo.

${ }^{5}$ Se dan casos parecidos en la historia de Kayūmart y la de Firīdún en los pasajes correspondientes a la muerte de sus hijos. Véase Ferdousí, 2015, pp. 13 y 72.

${ }^{6}$ En las versiones antiguas del mito, quien se duele por la muerte de la deidad vegetal es su madre/esposa, la Gran Diosa: la causante de su muerte/destierro. En el Shahnamé, estas dos funciones de la diosa se han dividido entre dos personajes: Sūdābé y Faranguīs. 
cia en aquel momento de los rituales de sūg en Sogdia, Corasmia y Persia (Biruní, 1984, pp. 363-368), especialmente en la ciudad de Bujará y sus alrededores (Narshají, 1984, p. 33), bajo el nombre de kìn-i Sìyāuruš [la venganza de Sīyāvušs] o geristan-i $m u \dot{g} a \bar{n}$ [el llanto de los Magos]. Además, el historiador turco Ahmet Zeki Velidi Togan (citado en Hosurí, 2006, pp. 93-95) habla de su continuidad en ceremonias luctuosas celebradas para personajes importantes, especialmente reyes o miembros de la nobleza, en el siglo x, y destaca los poemas épicos turcos llamados sūg-i Afrāsyāb, con un contenido muy similar. Por otro lado, los estudios realizados por Mehrdad Bahar (2014), Katayún Mazdapur (2004) y Abul Qasem Anyaví Shirazí (1984), entre muchos otros, revelan a su vez la continuidad de esta ceremonia en varios pueblos iraníes hasta la actualidad, especialmente en el centro y sur del país, con el nombre de $s \bar{i}$ yāoušān o sūvašūn, ${ }^{7}$ que al perder su sentido inicial en relación con el mito de Sìyāvuš, se han convertido en ritos luctuosos que se realizan cuando un miembro masculino joven de la familia pierde la vida. En otras palabras, la muerte injusta de los jóvenes virtuosos o inocentes se percibe como la muerte de Sìyāvuš y, por lo tanto, se realiza una ceremonia parecida a sūg-iSìyāous.

Sin embargo, la huella más importante de sūg en Irán se observa en la actual conmemoración luctuosa del martirio de Hussein, el tercer imán de los chiitas. Los investigadores están de acuerdo en que la práctica ritual del luto por Sīyāvuš es el antecedente más antiguo del teatro iraní y la base de la dramatización religiosa de ta'zìya (Beizaí, 1965, pp. 116-166; Hosurí, 2006, pp. 103-109), que se lleva a cabo anualmente en Irán en los primeros 10 días del mes de muharram del calendario árabe y que conmemora dicho suceso histórico. Asimismo, las similitudes (Beizaí, 1965, pp. 116-166; Hosurí, 2006, pp. 103-

${ }^{7}$ Hosurí (2006, pp. 108-116) refiere otras ceremonias parecidas que practican en la actualidad los nómadas qashqaí y bajtiarí de Irán y destaca la denominada čamar, practicada por la etnia lur. 
109) entre el ritual de siug-i Sìyāruš y las ceremonias de tāsū'a y $\bar{a} \bar{s} \bar{u} r \bar{a}^{8}$ son muy evidentes (el color negro en señal de luto, las procesiones, la flagelación y daño al cuerpo, el llanto, las canciones y la música fúnebre, por ejemplo) y los parecidos entre el personaje de Sīyāvuš y el del imán Hussein, también (su juventud, su lucha por la justicia, su inocencia y sus virtudes, su condición de víctima de una traición, la obligación de participar en una guerra injusta, su muerte sangrienta en un desierto, etcétera).

Por otro lado, en distintos pueblos del actual Irán hay otros rituales vinculados no con la muerte sino con la resurrección y la vida de Sìyāvušs, entre ellos mìr nowerūzí y kūsa barnišin (Razí, 1992, pp. 375-385). Este dato es interesante si consideramos que, según el Shabnamé de Ferdousí, una parte importante de la vida de Sīyāvuš transcurre en Irán, pues es un príncipe iraní, hijo del rey kayánida Kāvús, y nace y crece en Persia. De hecho, como se mencionó, el destierro al inframundo que culmina con la decapitación se narra en el Shabnamé como el exilio de Sīyāvuš en la tierra de los turcos, Tūrán. En otras palabras, para los iranios, Irán es el mundo de los vivos y Tūrán, la tierra enemiga, el inframundo. De ahí que el exilio y la muerte de Sìyāvuš traigan sequía a Irán, y que el regreso de su hijo Xusrow de Tūrán a Irán signifique la resurrección de Sìyāvuš manifiesta en la llegada de la primavera y la restauración de la naturaleza tras su muerte invernal. De este modo, las ceremonias rituales que recuerdan este regreso y resurrección son más comunes en Irán, que es lugar de vida, y los ritos relacionados con la muerte de Sīyāvuš están más presentes en Tūrán, actual Asia Central, donde la deidad fue asesinada. Mìr nowrūzí y kūsa barnišín son fiestas rituales relacionadas con el año nuevo y su función es evocar la fuerza vital de la primavera a través de la risa y la recreación del matrimonio sagrado entre la Gran Diosa y la deidad de las plantas (Bahar, 2014, pp. 398-399).

${ }^{8}$ Los días 9 y 10 del mes de muharram se libra la batalla en la cual el imán Hussein y sus 72 compañeros pierden la vida al enfrentarse a un ejército de miles de soldados en una guerra injusta, y sus familias sufren muerte, tortura y encarcelamiento. 
A su vez, Asia Central, especialmente Uzbekistán y Tayikistán, alberga los sitios ceremoniales más importantes para el ritual de süg, como Koi Krylgan Kala en Uzbekistán y Panjakent en Tayikistán. Como ocurre en Irán, los uzbekos y los tayikos ya no practican este ritual en su forma original; ${ }^{9}$ sin embargo, sus habitantes tienen memoria de él y algunas huellas se encuentran en la forma en que han tejido las leyendas relacionadas con varios de sus más significativos monumentos históricos. En el siguiente apartado expondré mi interpretación de algunas de estas leyendas, las cuales registré en trabajo de campo en ciudades uzbekas, especialmente Bujará, en relación con el mito de Sīyāvušs.

\section{Sīyāvuš y las leyendas uzbekas de los monumentos históricos de Bujará}

Bujará es la ciudad que, según la historia mítica de Irán y Asia Central, construyó Sīyāvuš. Quizá ésta sea la razón por la cual es la ciudad donde las leyendas que recogí tienen más cercanía con su mito. Para interpretarlas en ese marco, es necesario ubicar esta ciudad en el tiempo en que fueron construidos sus más importantes monumentos históricos. Parte de ellos pertenece a la época samánida (siglos IX y x), y otros, a la época timúrida (siglos XIV-XVI). Los samánidas eran una dinastía persa independiente establecida bajo el mandato del califato abásida y cuya formación coincide con movimientos patrióticos culturales en el territorio del imperio persa recientemente conquistado por los árabes musulmanes. Una de las manifestaciones más importantes de estos movimientos fue la composición de Libros

${ }^{9}$ En las fuentes secundarias a las que he accedido para este estudio no hay mención de rituales de sūg u otras ceremonias parecidas en Asia Central. Sin embargo, no descarto la posibilidad de que existan trabajos en otras lenguas, uzbeko y ruso, por ejemplo, que no hayan sido traducidos a lenguas accesibles para los investigadores que he consultado. Además, mi desconocimiento de dichas lenguas me ha impedido acceder personalmente a estas otras supuestas fuentes. 
de reyes o Shabnamés - entre los cuales destacan el Shahnaméde Abu Mansur Tusí y el Shahnamé de Ferdousí- con el fin de recuperar, a través de las leyendas épicas del pasado, la identidad cultural y la lengua persa frente a la amenaza del árabe y lo árabe-musulmán (Meskub, 2007).

La dinastía timúrida, a su vez, fue implantada después de las sangrientas invasiones mongolas en el siglo XIII por sus descendientes lejanos turcos, que, tras más de un siglo de haberse asentado en Irán y Asia Central, se habían convertido al islam y no sólo se habían dejado empapar por el gran legado civilizatorio de la zona, sino que se habían tornado en importantes mecenas de las artes y la cultura. Curiosamente, también en la época timúrida se volvieron a copiar los Libros de reyes, pero esta vez se trataba sólo del Shahnamé de Ferdousí, pues era el único que había sobrevivido hasta entonces. ${ }^{10}$ Bujará fue una de las capitales de los samánidas, y en la época timúrida, una ciudad privilegiada por su cercanía a Samarcanda, la capital de los timúridas. ${ }^{11}$

Hay que destacar que si bien el mazdeísmo en su forma originaria se desarrollaba en el mítico Tūrán desde el segundo milenio a.e.c., la llegada del islam también marcó una significativa pauta cultural para esta zona. Ahora bien, debido a la permanencia de dos siglos de los musulmanes persas samánidas, corrientes místicas como el sufismo también crecieron en la región, por lo que no sorprende observar que los elementos zoroastrianos, islámicos y sufíes se mezclan tanto en la arquitectura de los monumentos históricos de Bujará como en las

${ }^{10}$ Entre los Shahnamés de esta época que se conservaron íntegros y se guardan en museos del mundo, podemos nombrar el Shahnamé Baysongorí (encargado por Gias-al din Baysongor, rey timúrida, en 1426, actualmente parte de la colección Memory of the World Register de la UNESCO), uno de los manuscritos más voluminosos y artísticos de la obra (ilustrado con miniaturas de la escuela de Herat), y varias copias hechas en los siglos XIV y XV (1380-1480) en ciudades de Tabriz, Shiraz y Bagdad, bajo las dinastías turcomanas de Qara Quyunlu y Aq Qoyunlu.

${ }^{11}$ En los siglos posteriores, Bujará vio el establecimiento del janato de Bujará (siglos XVI-XVIII), seguido por el emirato de Bujará (siglos XVIII-Xx). Después todo el país formó parte de la Unión Soviética y, finalmente, en 1991, declaró su independencia. 
leyendas relacionadas con ellos. A todo esto hay que añadir la presencia constante de las leyendas míticas y épicas de los Shahnamés, especialmente del Shahnamé de Ferdousí, como libro escrito y como tradición oral. A continuación narro y analizo en este contexto algunas de estas leyendas vinculadas a los monumentos de Bujará.

\section{Kuban Diž o el Arg de Bujará}

El Arg de Bujará o la Fortaleza Antigua (kuhan diž en persa) es una fortificación que abarca más de cuatro hectáreas y durante su larga vida ha sido reconstruida varias veces. La leyenda central relacionada con ella es que fue erigida por Sīyāvuš. El Shabnamé de Ferdousí dice que Sīyāvuš construyó dos ciudades, ambas en Tūrán, y, según los textos sagrados del mazdeísmo, el Bundahišn en particular, una de ellas se fundó en el mundo material y la otra en el mundo minún (Dadaguí, 2012, p. 138). La creencia de los habitantes de Bujará es que su ciudad es la primera de ellas, la mundana, y el historiador uzbeko Abu Bakr Narshají, en su libro Tarij-e bujará, afirma lo mismo:

Ahmad bin Mohammad bin Nasr dice que Abul Hassan Neishaburí ha escrito en su libro Jazayin al-Ulum que la razón de la construcción de la Quhandiz de Bujará, es decir la muralla de la fortaleza de Bujará, fue que Sīyāvuš, hijo de Kāvús, escapó de su padre y cruzó el río Ŷiyhún y vino adonde estaba Afrāsyāb. Afrāsyāb lo recibió con amabilidad y le dio a su hija como esposa (y dicen algunos que le dio todo su reino). Sīyāvuš quiso que de él quedara una huella en este país, porque este país se le había prestado. Así que construyó esta muralla y solía estar allí. A Afrāsyāb le hablaron mal de Sīyāvuš y Afrāsyāb lo mató. Y lo enterraron bajo esta misma muralla en la puerta del este (la puerta de los vendedores de paja) y esta puerta la llaman ġūrìyān y ahí lo enterraron (Narshají, 1984, p. 32; la traducción es mía).

${ }^{12}$ Mundo espiritual o mundo de los arquetipos en la cosmovisión mazdeísta. 


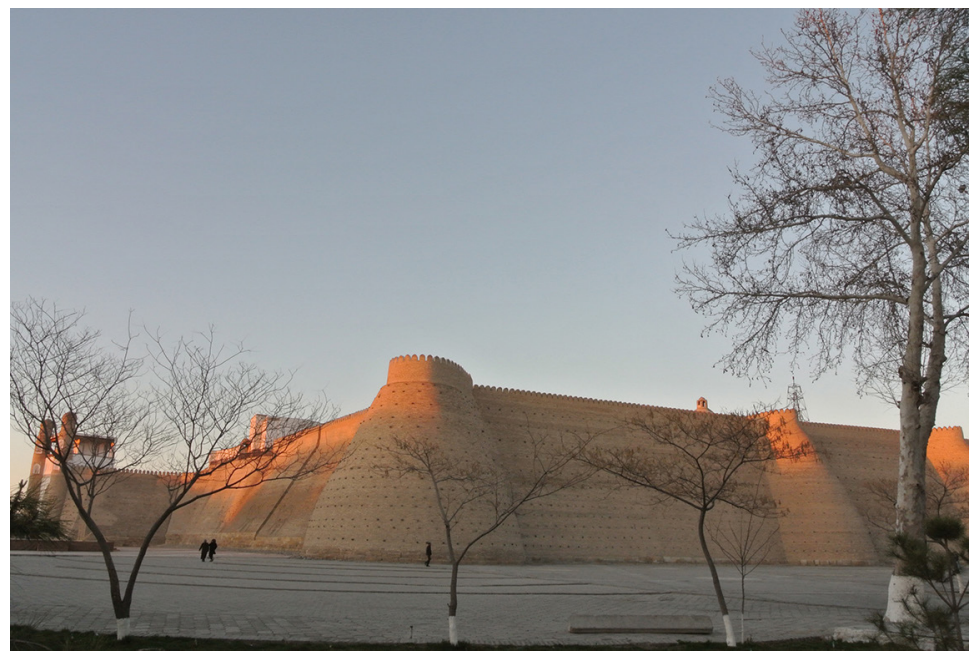

Imagen 1. Kuhan Diž o el Arg de Bujará. Fotografía de Shekoufeh Mohammadi Shirmahaleh, marzo de 2018.

Narshají (1984, p. 33) añade que "los Magos ${ }^{13}$ de Bujará lo consideran un lugar querido. Cada año, todos los hombres llevan ahí un gallo y lo sacrifican antes de que salga el sol de Nowrūz" (la traducción es mía). Esto evoca al Sīyāvuš mítico, deidad solar de las plantas, para quien se hacían sacrificios de animales relacionados con el sol, como el gallo, y cuya resurrección y regreso al mundo de los vivos es el comienzo de Nowrūz. Todavía hoy se localiza en la fortaleza el nicho donde los llamados Magos encendían velas por Sīyāvuš en la noche de Nowrūz y antes de este sacrificio. Narshají (1984, p. 33) también habla del ritual de luto por Sīyāvuš y dice: "Los habitantes de Bujará tienen muchos poemas luctuosos acerca de la muerte de Sīyāvuš, tantos que son famosos en todas las ciudades. Los músicos han compuesto canciones para ellos y las cantan. Los músicos sufíes

${ }^{13}$ Aquí la palabra mago hace referencia a los sacerdotes zoroastrianos. 
las llaman 'el llanto de los Magos'. Y esta palabra tiene más de tres mil años” (la traducción es mía).

Ahora bien, la leyenda acerca de la construcción de la fortaleza cuenta: ${ }^{14}$

Cuando Sīyāvuš vio a la hija de Afrāsyāb, Faranguīs, se enamoró de ella y quiso tomarla como esposa. Pero Afrāsyāb quería mucho a su hija y no estaba muy convencido de este matrimonio. Por lo tanto, pensó ponerle un obstáculo y probar así su inteligencia. Le dio el cuero de una vaca y le pidió que construyera una fortaleza sobre él. Sìyāvuš, tras una no muy larga reflexión, cortó el cuero en tiras muy finas, después unió las tiras y las colocó sobre el suelo en forma de un gran círculo y, sobre la superficie que abarcaba dicho círculo, construyó el Arg de Bujará. Afrāsyāb quedó maravillado y permitió que Sìyāvuš se casara con su hija (Otabek Karshiev, comunicación personal, 2018).

Al contrastar esta leyenda con la de Sīyāvuš en el Shahnamé de Ferdousí, se observa que el Shahnamé no contiene ninguna historia parecida. ${ }^{15}$ De hecho, escrito desde el punto de vista de los iranios, el príncipe persa no tiene ninguna intención de casarse, pero su belleza y sus virtudes son tan grandiosas que Afrāsyāb le toma cariño y desea tenerlo cerca como hijo propio, por esto le propone casarse con Faranguīs, y Sīyāvuš no rechaza la propuesta porque aceptar el cariño y la generosidad del rey le parece de buena educación. Además, Pìrán, el renombrado héroe turanio, le aconseja aceptar el ofrecimiento porque, al formar este lazo de unión, las largas guerras entre Irán y Türán podrían acabar (Ferdousí, 2015, pp. 359-360).

${ }^{14}$ Las leyendas que se citan fueron registradas a lo largo del trabajo de campo y en diferentes ciudades. Los entrevistados fueron mujeres y hombres uzbekos de entre 25 y 50 años. La mayoría de las leyendas de Bujará se recogieron cerca de los monumentos correspondientes; sin embargo, la relacionada con el Arg se contaba también en otras ciudades.

${ }^{15}$ Éste es un hecho interesante, porque las personas entrevistadas decían que lo que contaban proviene del Shabnamé de Ferdousí, que para ellos es un libro de historia. Esto hace pensar que quizá la leyenda haya formado parte de alguno de los Shahnamés de los siglos Ix y x que no sobrevivieron. 
Así pues, queda claro que la perspectiva de la leyenda uzbeka es distinta a la persa y se contrapone a ella porque le da protagonismo a Afrāsyāb, destaca la belleza y la importancia de Faranguīs y, por lo tanto, el deseo de Sīyāvuš por este matrimonio, así como la generosidad del rey de Tūrán, que en la visión iraní además de un terrible tirano es un monstruo, el dìv de la sequía (Avestá, 2013, pp. 922-923). Evidentemente, las virtudes del personaje de Sìyāvuš tampoco se le escapan a la leyenda y se plasman en la superación de una prueba complicada.

Otro elemento que llama la atención es que la fortaleza tenga como base el cuero de una vaca. En la mitología del mazdeísmo, la vaca es un símbolo femenino por excelencia y de ahí su relación con la fertilidad. Según el Bundahišn, de la semilla de la vaca primordial se crean todas las plantas y los cuadrúpedos beneficiosos (Dadaguí, 2012, pp. 37-41). Por lo tanto, la vaca está vinculada a la fertilidad de la tierra y la vitalidad de la naturaleza. Esta relación es muy significativa si recordamos la función de Sīyāvuš como deidad de las plantas, cuya muerte es sequía, y cuya resurrección, reverdecimiento. Así, en la leyenda uzbeka el cuero de la vaca, base de la fortaleza de Sìyāvušs, es un recordatorio de la función mítica del personaje y convierte este monumento en un lugar donde la vida está presente en plenitud.

Narshají también alude a algunas de las maravillas de esta fortificación, y entre ellas menciona que ninguno de los muchos reyes que la habitaron murió en ella, pues cuando se acercaba el momento de su fallecimiento, surgía algo y tenían que salir de la fortaleza y sucumbían en otro lugar (Narshají, 1984, p. 34). Esta afirmación refuerza la idea de la leyenda de que la fortaleza de Sìyāvuš es un lugar de vida, igual que él mismo es la deidad de la vida vegetal. De hecho, teniendo en cuenta las características geográficas de Bujará, la propia idea de que sea la ciudad edificada por Sīyāvuš se comprende en el marco del mito: Bujará es un oasis en medio del desierto, y qué mejor que la presencia en ella de una deidad de las plantas para justificar 
tanta exuberancia, que contrasta notoriamente con la aridez de las tierras que la rodean.

\section{El mausoleo de Ismael Samaní}

El mausoleo de Ismael Samaní, ubicado frente al Arg, a una distancia de un kilómetro, es un edificio construido en los siglos IX y x y alberga la tumba del rey Ismael, de la dinastía samánida (849-907). Ismael fue gobernante de Transoxiana y su reinado marcó un periodo cultural dorado en Asia Central y en el Irán oriental, en el sendero de otros reyes persas de la dinastía. La lengua de su reino fue el persa, y los monumentos que se construyeron bajo su mandato tienen como característica distintiva una interesante mezcla de elementos zoroastrianos e islámicos. El mausoleo imita la arquitectura de los an-

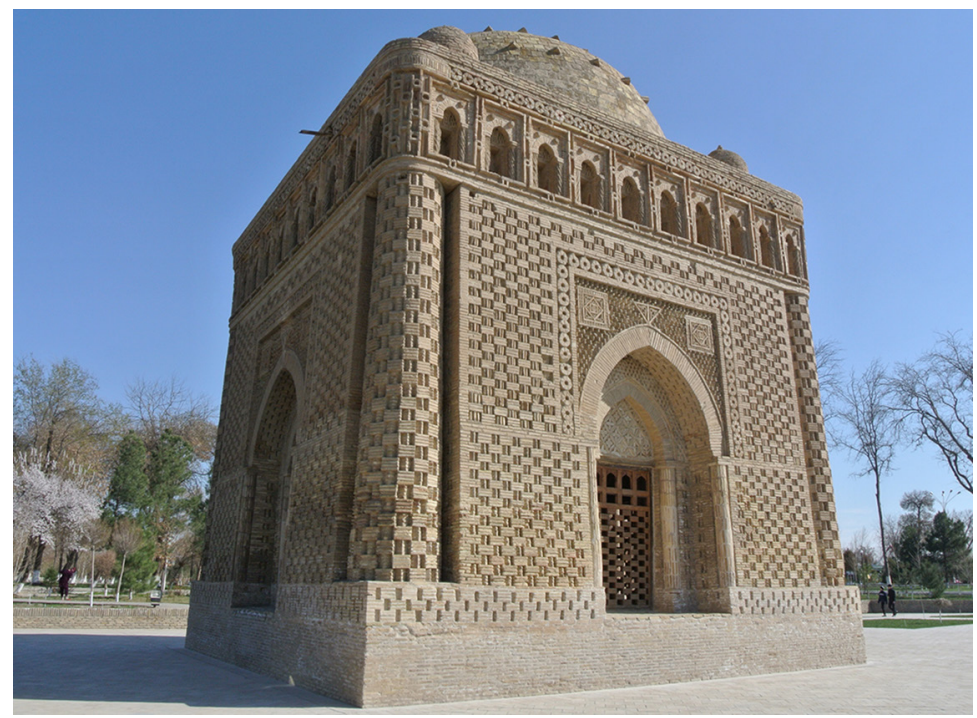

IMAGEN 2. Mausoleo de Ismael Samaní. Fotografía de Shekoufeh Mohammadi Shirmahaleh, marzo de 2018. 
tiguos templos de fuego persas y en su decoración abundan elementos solares, centrales en la cultura mazdeísta. Por lo tanto, hay una relación clara entre la figura de este rey y la cultura irania preislámica.

La leyenda que envuelve este monumento habla de la sabiduría del rey, de un saber que permanece incluso tras su muerte:

El rey Ismael era un hombre muy sabio y su reino era muy vivo. Cuando a la gente le sucedían cosas que no podía solucionar o tenía preguntas que nadie sabía contestar, iban a ver al rey y él siempre les daba una solución o una respuesta adecuadas. Cuando Ismael Samaní murió, lo enterraron en este mausoleo. Durante mucho tiempo la gente visitaba su tumba, y si tenían preguntas o consultas, las escribían en un papel que ponían sobre su lápida. A la mañana siguiente, cuando volvían, encontraban su respuesta, también escrita en papel, en el lugar donde habían dejado la pregunta. Dicen que hay pasadizos secretos que conectan el Arg y el mausoleo. Puede ser que los consejeros del rey, después de su muerte, cruzaran estos pasadizos, recogieran las preguntas y las respondieran sin ser vistos (Gulchikhra Fayziyeva y el Sr. Gulov, comunicación personal, 2018).

Lo primero que llama la atención en esta narración es la inmortalidad de la esencia del rey, su sabiduría, a pesar de la evidencia de la muerte de su cuerpo. Lo segundo es que, para explicar este suceso insólito, se hable de los pasadizos secretos entre el Arg y el mausoleo. Más allá de que dicho argumento intente justificar la continuidad de la esencia del rey en sus consejeros y ofrecer una explicación lógica para el milagroso suceso, es interesante observar la conexión que se establece entre ambas edificaciones y, por lo tanto, entre Ismael y Sìyāvuš. Ismael mandó construir el mausoleo igual que Sīyāvuš ordenó levantar la fortaleza; Ismael yace en este edificio, igual que Sīyāvušs, supuestamente, reposa bajo la puerta oriental de la fortaleza. Ismael es un rey constructor y sabio que le da "vida" al reino y la sede de su mandato es Bujará, todo lo cual es también cierto en el caso de Sīyāvuš. Finalmente, según la leyenda, aun muerto, Ismael sigue vivo, por lo que, 
al igual que Sìyāvušs, su muerte no es definitiva y su esencia es inmortal.

Es evidente que la leyenda del mausoleo tiene una clara relación con el mito de Sīyāvuš. Sìyāvuš muere y tiene una tumba, pero resucita tiempo después y realiza de nuevo su función como deidad vivificadora de las plantas; esta resurrección no es corporal, se trata del renacimiento de la esencia del dios. Ismael, a su vez, también muere, pero sigue cumpliendo su tarea, porque su esencia, la sabiduría, es inmortal. La conexión física de los dos edificios, a través de supuestos pasadizos secretos, confirma esta relación. Si consideramos la naturaleza cultural de la dinastía samánida, las características mazdeístas del edificio y la descripción histórica de la figura del rey Ismael como quien da nueva vida a Asia Central e Irán tras la conquista árabe y quien revive la lengua persa promoviendo la literatura de esta lengua (Meskub, 2007, pp. 36-44; Ashraf, 2008, pp. 13-14), dicho vínculo se refuerza todavía más: Ismael se lleva al terreno de la antigua civilización irania, cuna del mito de Sīyāvuš, y a través de esta leyenda su imagen se resignifica en el marco de la figura de la deidad fuertemente arraigada en Bujará, centro de las actividades de los samánidas.

\section{Kalān Minār}

A 500 metros de distancia, al poniente del Arg y encarando la puerta este de la fortaleza, está el complejo Pāy-i Kalān. Se trata de un conjunto religioso (una mezquita y una escuela) construido en torno a un minarete de 45 metros de altura que recibe el nombre de Kalān Minār [gran minarete]. El minarete es el edificio más antiguo y más conocido del complejo, construido en el siglo XII por el rey Arsalán Ján durante la dinastía Qarajánida; su estructura imita un faro y su función era señalar la ciudad de Bujará, señal que las caravanas que recorrían la Ruta de la Seda podían divisar desde lejos. Kalān Minār es el único monumento del complejo, y uno de los pocos de la 


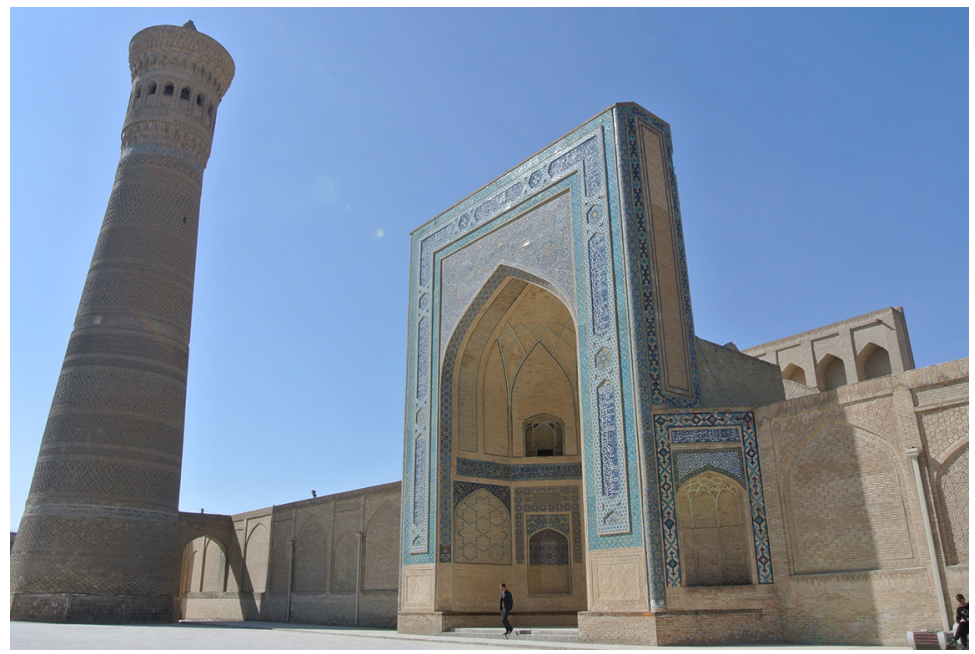

IMAGEN 2. Kalān Minār. Fotografía de Shekoufeh Mohammadi Shirmahaleh, marzo de 2018.

ciudad, que sobrevivió a la sanguinaria y destructiva invasión del ejército mongol en el siglo XIII y la quema de Bujará por Gengis Kan. ${ }^{16}$

Sorprende descubrir que el minarete es el monumento con más leyendas de la ciudad. Empero, aquí sólo narramos una de ellas, relacionada con su construcción:

El rey Arsalán Ján había ordenado que pusieran su trono en el atrio donde se encuentra actualmente el complejo Pāy-i Kalān. Ahí, encarando el Arg, el rey miraba pasar a la gente cuando descansaba. Quien pasara frente a su trono, al otro lado de la calle, tenía que doblegarse y rendirle respeto. Un día, un joven de la ciudad pasaba por ahí y se le olvidó hacerle una reverencia al rey. Arsalán Ján se enfadó y mandó que lo arrestaran. Posteriormente lo condenó a muerte por decapitación por haber cometido esta falta de respeto. Antes de que la condena se

${ }^{16} \mathrm{El}$ resto de los edificios del complejo fueron destruidos y quemados y su reconstrucción se llevó a cabo en el siglo Xvi. 
ejecutara, el rey le preguntó si tenía un último deseo. El joven contestó que su deseo era que, donde cayera su sangre, se construyera un edificio. Una vez que el joven fue decapitado en el atrio, el rey ordenó que construyeran el Kalān Minār donde se había derramado su sangre (Gulchikhra Fayziyeva, comunicación personal, 2018).

Para interpretar esta leyenda, es muy importante tener en cuenta la ubicación del minarete de Kalān: a poca distancia del Arg y al poniente de él. Esta ubicación se menciona en la narración, pues el rey se sentaba en el atrio mirando hacia el Arg y los transeúntes pasaban frente a él, "al otro lado de la calle", con la fortaleza como fondo. En realidad, el rey tenía de frente la puerta oriental de la fortaleza, donde se encuentra la tumba de Sīyāvuš. Esto cobra relevancia si se recuerda el argumento central de la leyenda: un joven inocente, caminando del lado del Arg, es víctima de la furia de un rey y muere decapitado. Donde cae su sangre surge un minarete, el más alto de la ciudad, símbolo de Bujará, el más antiguo del complejo, el único superviviente del fuego y la destrucción.

Aquí los puntos destacables son la inocencia del joven y su muerte injusta, la tiranía del rey y cómo su visión de la ciudad está relacionada con la muerte - porque mira hacia la tumba de Sìyāvuš- y el hecho de que de la sangre derramada del joven "nazca" y "crezca" un edificio. Todos estos elementos son centrales en la leyenda de Sīyāvuš según el Shahnamé de Ferdousí: él también es un joven inocente cuya sangre se derrama injustamente a causa de un tirano, y del lugar donde cae una gota nace una planta que simboliza la conservación de su esencia. Además, en ambos casos el asesinato ocurre por decapitación. Ahora bien, si recordamos que el Sīyāvuš mítico es una deidad solar y que sus rituales tienen que ver con la salida del sol en el día de Nowrūz, el hecho de que el minarete esté ubicado al poniente de la fortaleza se vuelve significativo: el joven de la leyenda es claramente un Sīyāvuš de épocas posteriores y el minarete que "crece" de su sangre está ubicado al poniente, donde muere el sol, y además encara la puerta oriental del Arg, la tumba de Sīyāvuš. Así se establecen paralelismos entre am- 
bas muertes, y si la fortaleza representa la vida de Sīyāvušs, el gran minarete se yergue como emblema de su muerte, simbolismo del que da fe la leyenda.

Por otro lado, que el minarete haya sobrevivido a un gran fuego recuerda otro punto de la historia de Sīyāvuš (Ferdousí, 2015, pp. 321-324): falsamente acusado de abuso por su madrastra, Sīyāvuš debe probar su inocencia cruzando una enorme fogata. Si sale indemne, es inocente, y si no, culpable. Sīyāvuš es puro, como la esencia misma del fuego, y el ardor de las llamas no le hace daño, sobrevive. Acto seguido comienza su exilio, llega a Tūrán y sabemos el resto. De modo parecido, el minarete nacido de sangre injustamente derramada, que carga con la esencia del joven inocente - del Sīyāvuš resignificado-, también se salva de un gran incendio y sigue siendo un símbolo por excelencia de la ciudad de Bujará, faro luminoso que guía a los viajeros, igual que en su tiempo, según el mito, lo fue Sìyāvuš mismo.

\section{Conclusiones}

A pesar del paso de los milenios, el mito de Sīyāvuš y su leyenda están vigentes en las zonas culturales donde se originaron. Esta presencia se refleja en leyendas derivadas del mito original, entremezcladas con elementos sociales, políticos y religiosos de épocas posteriores. Las leyendas que hoy se relacionan con algunos de los monumentos históricos más emblemáticos de Bujará son un claro ejemplo de esta continuidad a través de los siglos. En ellas están presentes los aspectos principales que constituyen el mito de Sìyāvuš: un joven virtuoso e inocente con función de constructor o vivificador, un tirano sanguinario, un injusto asesinato por decapitación y la inmortalidad de las virtudes de la víctima. Evidentemente, nuevos jóvenes virtuosos y tiranos han sustituido a Sīyāvuš y Afrāsyāb en estas leyendas, pero la esencia del mito se ha conservado. 
La ciudad de Bujará es hogar de muchas de estas leyendas, y la relación que Sīyāvuš tiene con ella, según el Shabnamé de Ferdousí y los historiadores, ha hecho que la permanencia de su mito sea más notoria. Asimismo, es interesante observar cómo la fortaleza Kuhan Diž, supuestamente construida por el príncipe persa, es el centro de estas leyendas y la forma en que se relacionan con ella los otros dos monumentos mencionados. En otras palabras, el vínculo entre las leyendas actuales y su mito originario no es sólo conceptual, sino también físico.

Las evidencias descubren la convivencia de dos grandes religiones, el mazdeísmo (en sus versiones persas, corasmias y sogdianas) y el islam, en las sedes importantes de la cultura irania, como Irán y Asia Central. A pesar de que los países de la zona han visto pasar distintos sistemas políticos y sociales, y se han regido por calendarios también diferentes, a través de estas leyendas la visión mítica del mundo y la circularidad de su percepción temporal están latentes en la vida de sus habitantes hoy en día.

\section{Referencias}

Anyaví Shirazí, A. Q. (1984). Ferdousinamé [Libro de Ferdousí] (vol. 3). Teherán: Elmí.

AsHraf, A. (2008). Hoviat-e iraní be se ravayat [Tres perspectivas de la identidad iraní]. Irannameh, (24), 1-21.

Avestá (2013). (Ed. y trad. Y. Dustjah) (2 vols.). Teherán: Morvarid. BaHAr, M. (2014). Pajuheshi dar asatire irán [Indagaciones en la mitología irania]. Teherán: Agah.

Beizaí, B. (1965). Namayesh dar irán [Teatro en Irán]. Teherán: Kavián.

BIRUNí, A. R. (1984). Asar-ul-bagiyah'an quroon-ul-kbaliya [Las huellas conservadas de los siglos pasados] ( $3^{\mathrm{a}} \mathrm{ed}$.) (Trad. A. Danaseresht). Teherán: Amir Kabir.

DADAGUí, F. (2012). Bundahišn (Ed., trad., introd. y notas M. Bahar). Teherán: Tus. 
Ferdousí, A. Q. (2015). Shahnamé (vol. 1) (Ed. Y. Jalequí Motlagh). Teherán: Soján.

Hosurí, A. (2006). Siyarwushán (2a ed.). Teherán: Cheshmé.

MAZDAPUR, K. (2004). Tadavom-e adab-e kohan dar rasmhaye moasere zartoshtián dar irán [Vigencia de viejas narrativas en los rituales zoroastrianos contemporáneos]. Farbang, 49-50, 147-179.

Meskub, S. (2007). Hoviat-e iraní va zaban-e farsí [La identidad iraní y la lengua persa]. Teherán: Pajuhesh Farzán Ruz.

Narshají, A. B. M. bin Y. (1984). Tarij-e Bojará [La historia de Bujará] ( $2^{a}$ ed.) (Ed. y notas S. M. T. Modarres Razaví; trad. A. N. A. bin M. bin Nasr Alqabavi,). Teherán: Tus.

Ne'mat Tavusí, M. (2013). Siyawash va izad-e nabatat. En G. Dabiri y O. Grabar (Eds.), Shahnamé va pajuhesh-haye tazé: piramune tarikhnegari, honar va jame.eye iraní [El Shahnamé y nuevas investigaciones: acerca de la historiografía, el arte y la sociedad iraníes] (Trad. M. Fazelí Biryandí) (pp. 49-66). Teherán: Payán.

RAzí, H. (1992). Gabshomarí va yashnha-ye iran-e bastán [El conteo del tiempo y las festividades del Irán antiguo]. Teherán: Behyat.

Tabarí, M. b. Y. (1990). Tarij-e Tabarí [La historia de Tabarí]. (Trad. A. Qasem Payandé) (vol. 1). Teherán: Asatir.

Tha'Alibí Neishaburí, A. (1970). Tarij-e Tha'alibi: Ghurar Akbbar Muluk al-Furs wa Siaribim [La historia de Tha'alibí: crónicas de los reyes persas y sus hazañas]. (Trad. y nota preliminar M. Fazaelí; introd. H. Zotenberg). Teherán: Noqré.

Tolstov, S. P. (1984a). Древний Хорезм: Onыт историкоархеологического исследования [Antigua Corasmia. Ensayo de investigación histórico-arqueológica]. Moscú: MSU.

Tolstov, S. P. (1984b). По следам древнехорезмийской ичивилизащии [Siguiendo las huellas de la antigua civilización de Corasmia]. Moscú: MSU.

Shekoufeh Mohammadi Shirmahaleh es doctora en lingüística aplicada por la Universidad de Alicante. Su carrera profesional ha consistido en investigación, docencia y traducción. Actualmente es investigadora del Seminario de Hermenéutica del Instituto de Investigaciones Filológicas de la UNAM, y se 
ha dedicado a las aplicaciones de la semiótica a la literatura y las artes, con la cultura y el arte persas como el centro de sus estudios. Sus líneas de investigación incluyen la hermenéutica literaria, la hermenéutica del mito y el símbolo y la hermenéutica cultural. Es profesora de asignatura de literatura universal en la Facultad de Filosofía y Letras, y de teorías de la significación en la Facultad de Ciencias Políticas y Sociales, ambas de la UNAM.

https://orcid.org/0000-0003-4660-8938 smohammadi@comunidad.unam.mx 